\title{
PERFIL EPIDEMIOLÓGICO DE CASOS DE TUBERCULOSE INFANTOJUVENIL NO BRASIL
}

\author{
EPIDEMIOLOGICAL PROFILE OF TUBERCULOSIS CASES IN CHILDREN \\ AND ADOLESCENTS IN BRAZIL
}

Anna Maria Andrade Barbosa", Bernardo Malheiros Tessari, Bárbara de Oliveira Arantes, Yuri Borges Bitu de Freitas, Antonio Márcio Teodoro Cordeiro Silva.

Pontifícia Universidade Católica de Goiás, Goiânia, GO, Brasil.

*annamandrade@icloud.com

\section{RESUMO}

Apesar da tuberculose (TB) ser uma doença evitável e curável, trata-se um importante problema de saúde pública, sendo considerada, pela Organização Mundial de Saúde (OMS), como uma emergência mundial. A TB infantil representa acontecimento-sentinela, sinalizando o contacto com um adulto ou adolescente bacilífero, o que obriga a um inquérito epidemiológico, rastreio dos contatos e tratamento dos indivíduos doentes. Em crianças com até aos cinco anos de idade, tanto o risco de progressão para doença ativa, como o de desenvolvimento de quadros clínicos mais graves são inversamente proporcionais à idade, uma vez que, nesta faixa etária, existe algum grau de compromisso da resposta imunológica. Diante desse panorama tem-se por objetivo descrever o perfil epidemiológico da tuberculose, em crianças e adolescentes, até 19 anos, no Brasil, analisando os dados de região do país, faixa etária, sexo, etnia, coinfecção com HIV, abandono do tratamento, cura e evolução para óbito, na população estudada por meio de estudo epidemiológico, sobre TB em crianças e adolescentes, no período de 2001 a 2019, no território nacional, com informações referentes à tabulação e interpretação dos dados extraídos do Sistema de Agravos de Notificação (SINAN), disponibilizados pelo DATASUS. Sob a luz da análise de dados em relação à distribuição demográfica, a região Sudeste permaneceu com os maiores números de casos confirmados de tuberculose, em menores de 19 anos, durante todo o período analisado. Já a região Centro-Oeste teve os menores valores. Todavia, ambas as regiões tiveram decréscimo desses índices, quando comparados os anos de 2001 e 2019; na região Sudeste houve diminuição de 10\% e na Centro-Oeste, de $43 \%$. Analisando a prevalência: por sexo, o masculino foi responsável por $55 \%$ do total; por faixa etária, $64 \%$ dos pacientes tinham de 15 a 19 anos; e, por etnia, a parda teve $40 \%$ do total de casos de tuberculose. Entretanto, $23 \%$ dos casos tiveram a etnia ignorada ou deixada em branco. Já sobre a questão da coinfecção com HIV, a positividade ocorreu em $3 \%$ dos casos. É importante ressaltar a grande quantidade de casos, com testes ignorados/brancos, em andamento e não realizados; 0,2\%, 7\% e 43\%, respectivamente. Em 10\% dos casos, houve abandono do tratamento, em $74 \%$ cura e, em $0,8 \%$, óbito. A faixa etária de menor de 1 ano obteve os piores índices, com menor percentual de cura e maior de óbitos, $63 \%$ e 2,6\%, respectivamente. O melhor prognóstico observado foi na faixa de 10 a 14 , com $77,6 \%$ de cura e $0,6 \%$ de óbito. Portanto, 
vale evidenciar que foram observadas diminuições nos casos de tuberculose, em diferentes contextos, alta prevalência dos índices de óbito e mortalidade em relação à população jovem, na faixa etária de menores de 1 ano. Vale lembrar da população masculina e parda, não concomitantemente, como maiorias afetadas. Ressalta-se carência de informações relativas à etnia e aos testes ignorados/brancos, como limitação do estudo.

Palavras-chave: Brasil. Doenças infecciosas. Epidemiologia. Mycobacterium. Tuberculose infantil. 